\title{
Are Taxonomic Distinctness measures compliant to other ecological indicators in assessing ecological status?
}

\author{
F. Salas ${ }^{\text {a,* }}$, J. Patrício ${ }^{\text {b }}$, C. Marcos ${ }^{\text {a }}$, M.A. Pardal ${ }^{\text {b }}$, A. Pérez-Ruzafa ${ }^{\text {a }}$, J.C. Marques ${ }^{\text {b }}$ \\ a Department of Ecology and Hydrology, Faculty of Biology, University of Murcia, 30100 Murcia, Spain \\ ${ }^{\mathrm{b}}$ IMAR - Institute of Marine Research, clo Department of Zoology, Faculty of Sciences and Technology, \\ University of Coimbra, 3004-517 Coimbra, Portugal
}

\begin{abstract}
Assessing the ecological status, a concept implemented in the European Water Framework Directive [EC, 2000. Directive of the European Parliament and of the Council 2000/60/EC establishing a framework for community action in the field of water policy PE-CONS 3639/1/00, p. 72], requires the application of methods capable of distinguishing different levels of ecological quality. The Average Taxonomic Distinctness has been used as tool in this context, and we tested the robustness of Taxonomic Distinctness measures applying it in different scenarios (estuarine eutrophication, organic pollution, and re-colonisation after physical disturbance), analysing simultaneously its compliance to other types of ecological indicators. Results show that, in most of the case studies, only Total Taxonomic Distinctness was relatively satisfactory in discriminating between disturbed situations. Other Taxonomic Distinctness measures have not proved to be more sensitive than other ecological indicators (Shannon-Wiener, Margalef, and Eco-Exergy indices). Therefore, this approach does not seem to be particularly helpful in assessing systems' ecological status with regard to the WFD implementation.
\end{abstract}

(C) 2006 Elsevier Ltd. All rights reserved.

Keywords: Taxonomic Distinctness measures; Diversity; Eco-Exergy; Specific Exergy; Ecological status; European Water Framework Directive

\section{Introduction}

The EC's Water Framework Directive (EC, 2000) establishes a framework for the protection of all waters (including inland surface waters, transitional waters, coastal waters, and groundwater), aiming at achieving good quality status for all waters by 2015 . The concept of ecological status developed in the WFD is defined in terms of the quality of the biological community, as well as the systems' hydrological and chemical characteristics. Applying it requires methods capable of distinguishing different levels of ecological quality to classify surface water areas. Moreover, the concept of ecological status implies that in the

DOI of original article: $10.1016 /$ j.marpolbul.2005.08.014

DOI of Publisher's note: 10.1016/j.marpolbul.2006.06.003

* Corresponding author.

E-mail address: fuenmar@um.es (F. Salas). absence of a comprehensive knowledge of all the pressures on a water body and of their combined biological effects, it will always be necessary to get direct measures with regard to the condition of the biological quality elements. This must be achieved, namely, by using biological indicators, in order to validate any biological impacts suggested by non-biological indicators. Therefore, the WFD highlights the importance of measures able to elucidate the biological effects of disturbance.

At least in theory, all ecological indicators accounting for the composition and abundance of biological communities might be useful in detecting the environmental situation of an ecosystem. Costello et al. (2004) surveyed the frequency of using diversity indices in the scientific literature and found that the most widely used and popular measure of diversity is species richness (e.g. number of species, Margalef index), immediately followed by the ShannonWiener and evenness indices. Although, highly applied, some authors (Warwick and Clarke, 1998; Wilkinson, 
1999; Rogers et al., 1999; Gray, 2000) point out that these measures can be highly influenced by different sample sizes, sampling effort, habitat type or complexity, and do not show monotonic behaviour in response to environmental degradation. Finally, the Convention on Biological Diversity (UNEP, 1992) argues that biodiversity cannot be regarded as just the number of species in an area or measured by an index of their relative abundance. In the Rio declaration, biodiversity was defined as "the variability among living organisms including, for example, terrestrial, marine and other ecosystems and the ecological complexes to which they belong: this includes diversity within species, between species and diversity of ecosystems". Almost all of the components of natural systems are therefore included in this definition of biodiversity. This broad definition resulted in many different interpretations of the biodiversity concept when put into practice. According to Van der Spoel (1994), biodiversity must be considered as "the sum of taxonomic or numerical diversity, and the ecological, genetic, historical and phylogenetic diversity. In this context, Warwick and Clarke (1995) proposed that Taxonomic Distinctness measures should incorporate more of this information than species richness measures. Although there were some attempts to use Taxonomic Distinctness measures more widely in the marine field (Somerfield et al., 1997; Hall and Greenstreet, 1998; Rogers et al., 1999; Clarke and Warwick, 2001;
Warwick and Light, 2002; Warwick et al., 2002), these measures still need a wider testing and should be investigated, as these indices are likely to add complementary information value to existing measures of biodiversity (Costello et al., 2004). In this paper we test the robustness of Taxonomic Distinctness measures applying it in different scenarios (estuarine eutrophication, organic pollution, and re-colonisation after physical disturbance) and, simultaneously, analysing its compliance to other types of ecological indicators (Shannon-Wiener, Margalef and Eco-Exergy indices). The aim was to evaluate their effectiveness as pollution/disturbance biological indicator with regard to the European Union Water Framework Directive implementation.

\section{Materials and methods}

\subsection{Case studies and data source}

\subsubsection{Mondego estuary (Portugal)}

The Mondego estuary (Fig. 1A) is under severe environmental stress, and an ongoing eutrophication process has been monitored during the last decade. A detailed description of the characteristics of the system can be found in the available literature (e.g. Marques et al., 1997, 2003; Pardal et al., 2000, 2004; Martins et al., 2001; Cardoso et al., 2004).

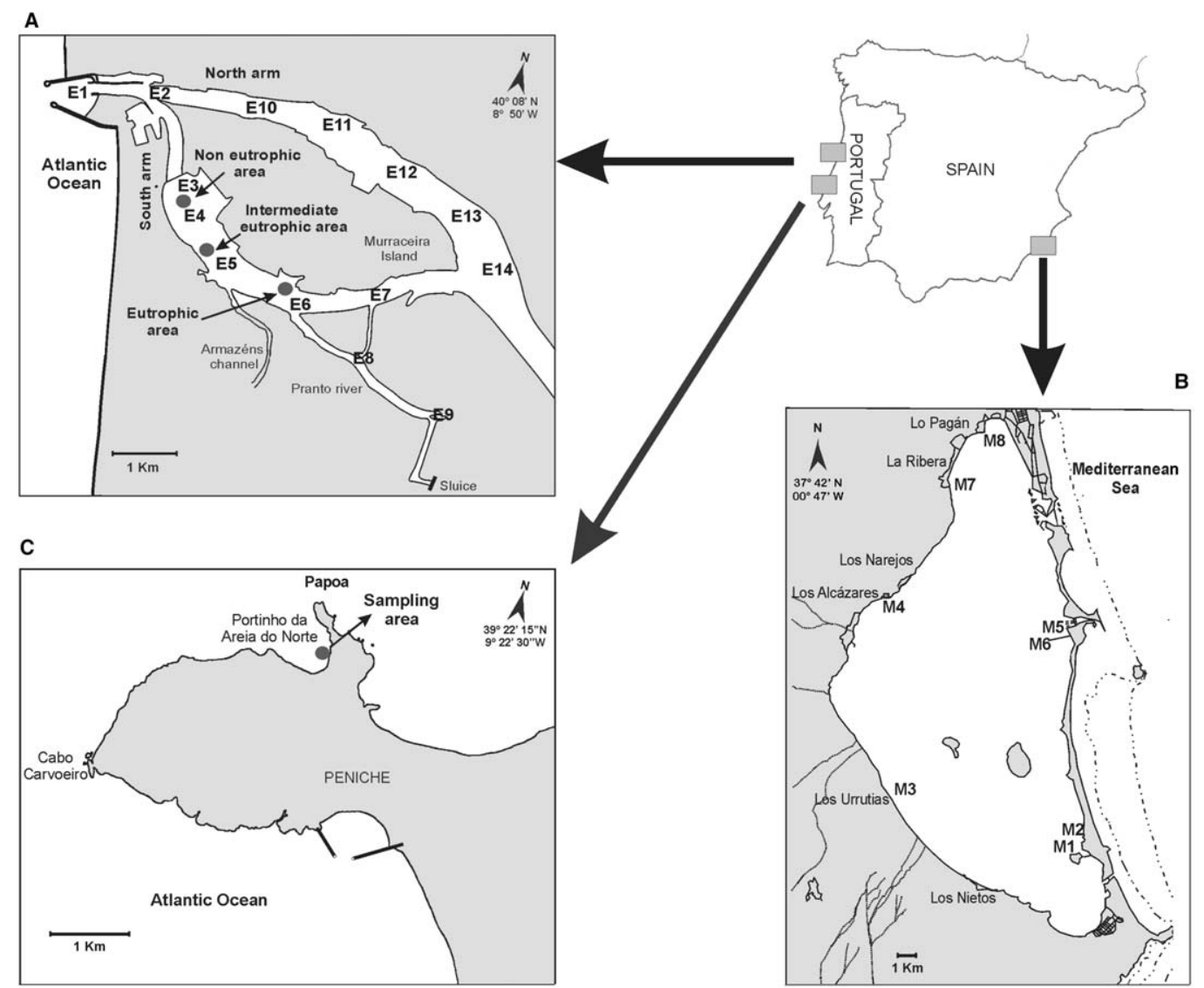

Fig. 1. Case studies location. A: Mondego estuary (Portugal), B: Mar Menor (Spain) and C: Papoa (Portugal) and sample stations. 
Two different data sets were selected: (a) subtidal communities and (b) intertidal communities. The first set was provided by a study on the subtidal soft bottom communities, which characterised the whole system with regard to species composition and abundance, taking into account its spatial distribution in relation to the physicochemical factors of water and sediments. The infaunal benthic macrofauna was sampled using a van Veen grab $\left(496 \mathrm{~cm}^{2}\right)$ during spring, in 1990, 1992, 1998 and 2000, at 14 stations (E1 to E14) (five replicates in each station) covering the whole system (Fig. 1A). The second set proceeded from a study on the intertidal benthic communities carried out from February 1993 to February 1994 in the south-arm of the estuary (Fig. 1A). Samples of macrophytes, macroalgae and associated macrofauna, as well as samples of water and sediments, were taken fortnightly, with a manual core $\left(141 \mathrm{~cm}^{2}\right.$ to a depth of $\left.15 \mathrm{~cm}\right)$, during low water, at three areas, representing different conditions along a spatial gradient of eutrophication symptoms (Fig. 1A): a non-eutrophic area (Zostera noltii beds), an intermediate eutrophic area (Zostera noltii absent, although residual roots can still be found in the sediment) and a strongly eutrophic area (macrophyte community totally absent with Ulva sp. blooms regularly observed). In both studies, samples were preserved in $4 \%$ buffered formalin and sieved through a $1 \mathrm{~mm}$ mesh (subtidal community) and $500 \mu \mathrm{m}$ mesh (intertidal communities). Organisms were identified to the species level and their biomass was determined $\left(\mathrm{g} \mathrm{m}^{-2}\right.$ AFDW). Corresponding to each biological sample the following environmental factors were determined: salinity, temperature, $\mathrm{pH}$, dissolved oxygen, silica, chlorophyll a, ammonia, nitrates, nitrites, and phosphates in water, and organic matter content in sediments.

\subsubsection{Mar Menor (Spain)}

The Mar Menor is a coastal lagoon with an area of $135 \mathrm{~km}^{2}$. The lagoon is connected to the Mediterranean at some points by channels through which the water exchange takes place with the open sea (Fig. 1B). This coastal lagoon presents an environmental heterogeneity with different types of pollution sources. A detailed description of the system and of the effects of the main environmental impacts to which it is subject to can be found in the available literature (e.g. Pérez-Ruzafa et al., 1987, 1989, 1991, 2000, 2005; Barcala, 1999).

Data from Pérez-Ruzafa et al. (1989), consisting of a complete characterisation of the benthic populations in the lagoon, were used. Eight sampling stations were located on both rocky and soft bottoms along the lagoon at sites representative of the different biocenosis and main polluted areas (Fig. 1B): rocky bottom stations M7 and M8 (urban direct dumping with the development of nitrophyle communities dominated by Ulva sp.); rocky bottom stations M1 and M5 (not affected by organic enrichment); stations M2 and M6 (with high levels of organic matter in the sediment coming from the primary production of the macrophyte meadows (Caulerpa prolifera) that was introduced in the lagoon as a result of the dredging in one of the channels at the beginning of the 1970s, growing rapidly around the whole lagoon (Pérez-Ruzafa et al., 1991), leading to an increment of the organic matter in the sediment, which had important effects in the biological communities, namely a general impoverishment with regard to macrofauna) and, finally, stations M3 and M4 located in soft bottom zones with low input of organic matter $(<1 \%)$.

Samples were taken seasonally (A: July, B: November, C: February, D: May), which allowed evaluating the influence of seasonal variations on the performance of different ecological indices. Divers collected biological samples from both soft bottoms and rocky areas, moving along transepts perpendicular to the coastline and also in precise spots corresponding to the eight sampling stations. Each sample corresponded to $400 \mathrm{~cm}^{2}$. Afterwards, samples were sieved through a $500 \mu \mathrm{m}$ mesh and preserved in $4 \%$ buffered formalin in seawater. Organisms were identified to the species level and biomass was determined $\left(\mathrm{g} \mathrm{m}^{-2}\right.$ AFDW). The environmental factors measured were salinity, temperature, $\mathrm{pH}$, and dissolved oxygen, as well as sediment particles size, organic matter and heavy metal contents.

\subsubsection{Papoa (Portugal)}

Data used are the outcome of a re-colonisation field experiment carried out from February 1999 to May 2000 in a small beach, Papoa, on the Western Coast of Portugal (Fig. 1C), where the intertidal community is dominated by the turfing algae Corallina elongata which forms a stiff matrix that held some sediment (Patrício et al., in press). Other red macroalgae (e.g. Chondria sp., Chondrachantus sp., Gigartina sp. and Laurencia sp.) and green macroalgae (Cladophora sp. and Ulva sp.) also occur as epiphytes or as early successional species. In February 1999, quadrates of $25 \times 25 \mathrm{~cm}\left(625 \mathrm{~cm}^{2}\right)$ were randomly distributed across the study area. During the preparation phase, 27 discrete areas were created by totally removing macroalgae and the associated macrofauna with a chisel. Other plots were assigned as controls, being left undisturbed at this stage of the experiment. Subsequently, both experimental plots (three replicates) and control plots were sampled, during low tide, every one or two months, until May 2000. Samples were preserved in $4 \%$ buffered formalin in seawater and sieved through a $500 \mu \mathrm{m}$ mesh. Later, algae and associated macrofauna were separated, identified to the species level and biomass ( $\mathrm{g} \mathrm{m}^{-2}$ AFDW) assessed after combustion of samples for $8 \mathrm{~h}$ at $450{ }^{\circ} \mathrm{C}$.

\section{Data analysis}

\subsection{Taxonomic Distinctness measurements}

To estimate Taxonomic Diversity indices, a hierarchical Linnean classification was used as a proxy for cladograms representing the relatedness of individual species. For each location, a composite taxonomy was compiled and five taxonomic levels were considered (species, genus, family, 
order, class and phylum) and five diversity indices (Taxonomic Diversity, $\Delta$; Taxonomic Distinctness, $\Delta^{*}$; Average Taxonomic Distinctness based on presence/absence of species $\Delta^{+}$; Variation in Taxonomic Distinctness $\Lambda^{+}$and Total Taxonomic Distinctness, $s \Delta^{+}$) defined by Clarke and Warwick $(1998,2001)$ were then calculated from macrofauna abundances, using PRIMER 5 (Software package from Plymouth Marine Laboratory, UK):

$\Delta=\left[\sum \sum_{i<j} \omega_{i j} x_{i} x_{j}\right] /[n(n-1) / 2]$

$\Delta^{*}=\left[\sum \sum_{i<j} \omega_{i j} x_{i} x_{j}\right] /\left[\sum \sum_{i<j} x_{i} x_{j}\right]$

$\Delta^{+}=\left[\sum \sum_{i<j} \omega_{i j}\right] /[s(s-1) / 2]$

$\Lambda^{+}=\left[\sum \sum_{i \neq j}\left(\omega_{i j}-\bar{\omega}\right)^{2}\right] /[s(s-1)]$

$s \Delta^{+}=\sum_{i}\left[\left(\sum_{i \neq j} \omega_{i j}\right) /(s-1)\right]$

where $x_{i}$ represents the abundance of the $i$ th of $s$ species observed, $n\left(=\sum_{i} x_{i}\right)$ is the total number of individuals in the sample and $\omega_{i j}$ is the "distinctness weight" given to the path length linking species $i$ and $j$ in the taxonomy. Taxonomic Diversity (Eq. (1)) can be thought of as the average path length between two randomly chosen individuals from the sample (including individuals of the same species), whereas Taxonomic Distinctness (Eq. (2)) is the average path length between two randomly chosen individuals, conditional on them being from different species (Rogers et al., 1999). From data consisting only of presence or absence of species (i.e., species list), a simpler form of Taxonomic Distinctness (Eq. (3)), can be thought of as the average length between any two randomly chosen species present in the sample. The degree to each certain taxa are over- or under-represented in samples is another biodiversity attribute of ecological relevance and it is reflected by the Variation in Taxonomic Distinctness (Eq. (4)). Finally, Total Taxonomic Distinctness (Eq. (5)) was proposed by Clarke and Warwick as a useful measure of total taxonomic breadth of an assemblage, as a modification of species richness, which allows for the species interrelatedness.

\subsection{Diversity measures}

The Shannon-Wiener (Eq. (6)) and Margalef indices (Eq. (7)) were applied.

$$
\begin{aligned}
& H^{\prime}=-\sum p_{i} \log _{2} p_{i} \\
& D=(S-1) / \log (N)
\end{aligned}
$$

where $p_{i}$ is the proportion of abundance of species $i$ in a community were species proportions are $p_{i}, p_{2}, p_{3}, \ldots p_{n}, S$ is the number of species found and $N$ is the total number of individuals.

\subsection{Eco-Exergy and Specific Exergy}

Eco-Exergy (Eq. (8)), a concept derived from thermodynamics, was also estimated for each location. Eco-Exergy (Jørgensen and Mejer, 1979) is one of the mathematical functions that have been proposed as holistic ecological indicators in the last two decades, intending a) to express emergent properties of ecosystems arising from self-organisation processes in the run of their development, and b) to act as orientors (goal functions) in models development. Eco-Exergy, which has been tested in several studies, can be seen as a measure of the maximum amount of work that the system can perform when it is brought into thermodynamic equilibrium with its environment. If Eco-Exergy is calculated only from the chemical potentials, which are extremely dominant with regard to ecosystems, the following expression is valid with good approximation (Jørgensen, 2002):

$E x=R T \times \sum C_{i} \times \beta_{i}$

where $R$ is the gas constant, $T$ is the absolute temperature and $C_{i}$ is the concentration in the ecosystem of component $i$ (e.g. biomass of a given taxonomic group or functional group). $\beta_{i}$ is a factor able to express roughly the quantity of information embedded in the biomass. $\beta$-values have previously been calculated for several organisms based upon number of coding genes (see Jørgensen, 2002). Detritus was used as reference level, i.e. $\beta_{i}=1$ and Eco-Exergy in biomass of different types of organisms is expressed in detritus energy equivalents. This formulation does not correspond to the strict thermodynamic definition, but provides nevertheless an approximation of Exergy values. In this sense it was proposed to call it Eco-Exergy Index (Marques et al., 1997).

If the total biomass in the system remains constant through time, then the variation of Exergy will be a function of only the structural complexity of the biomass or, in other words, of the information embedded in the biomass, which may be called Specific Exergy (SpEx) or Exergy per unit of biomass (Eq. (9)). For each instant, Specific Exergy is given by:

$\mathrm{SpEX}=\frac{\text { Exergy }}{\text { Biom }_{\text {tot }}}$

\subsection{Statistical analysis}

Pearson's correlations $(p \leqslant 0.05)$ were estimated to evaluate the relationships between the values of the indices and environmental factors. Moreover, the values estimated for each index were submitted to a Kruskal-Wallis analysis to test their performance in detecting differences (a) along spatial and temporal gradients, in the case of the Mondego estuary data set, (b) between organic enriched and non- 
Table 1

Indices values in Mondego estuary (subtidal stations) in 1990, 1992, 1998 and 2000

\begin{tabular}{|c|c|c|c|c|c|c|c|c|c|c|c|c|}
\hline & \multicolumn{4}{|l|}{ E1 } & \multicolumn{4}{|l|}{ E2 } & \multicolumn{4}{|l|}{ E3 } \\
\hline & 90 & 92 & 98 & 00 & 90 & 92 & 98 & 00 & 90 & 92 & 98 & 00 \\
\hline$S$ & - & - & 15 & 10 & 4 & 7 & 6 & 26 & 8 & 10 & 1 & 7 \\
\hline Shannon & - & - & 2.85 & 0.87 & 1.56 & 1.74 & 2.45 & 3.45 & 2.56 & 2.94 & 0 & 2.55 \\
\hline Margalef & - & - & 2.32 & 1.30 & 0.91 & 1.26 & 1.35 & 4.01 & 1.47 & 2.01 & 0 & 1.74 \\
\hline$\Delta$ & - & - & 71.9 & 22.9 & 55.9 & 47.6 & 73.6 & 73.6 & 72.5 & 71.7 & 0 & 75.9 \\
\hline$\Delta^{*}$ & - & - & 93.6 & 97.2 & 95.4 & 87.2 & 95.1 & 86.2 & 92.3 & 84.1 & 0 & 92.7 \\
\hline$\Delta^{+}$ & - & - & 92.4 & 85.6 & 97.2 & 83.3 & 88.3 & 90.5 & 90.5 & 87.1 & 0 & 91.3 \\
\hline$s \Delta^{+}$ & - & - & 1386 & 856 & 388 & 583 & 442 & 2353 & 633 & 870 & 0 & 639 \\
\hline$\Lambda^{+}$ & - & - & 207 & 390 & 39 & 476 & 336 & 296 & 280 & 579 & 0 & 255 \\
\hline Eco-Ex & - & - & 214 & 3528 & - & - & 32 & 3425 & - & - & 6 & 15 \\
\hline \multirow[t]{2}{*}{ Sp Eco-Ex } & - & - & 100 & 276 & - & - & 219 & 217 & - & - & 450 & 65 \\
\hline & \multicolumn{4}{|l|}{ E4 } & \multicolumn{4}{|l|}{ E5 } & \multicolumn{4}{|l|}{ E6 } \\
\hline$S$ & 18 & 6 & 6 & 8 & 19 & 10 & 9 & 11 & 10 & 9 & 9 & 9 \\
\hline Shannon & 3.11 & 2.42 & 1.43 & 2.92 & 1.22 & 2.74 & 2.03 & 2.51 & 0.72 & 1.88 & 1.91 & 1.46 \\
\hline Margalef & 3.15 & 1.47 & 0.94 & 1.99 & 2.11 & 1.91 & 1.07 & 1.35 & 1.18 & 1.32 & 1.25 & 1.03 \\
\hline$\Delta$ & 72.0 & 76.6 & 42.9 & 82.1 & 28.2 & 76.9 & 49.5 & 67.8 & 16.0 & 61.1 & 51.9 & 46.7 \\
\hline$\Delta^{*}$ & 91.1 & 93.8 & 95.1 & 92.6 & 84.7 & 94.7 & 81.7 & 87.4 & 86.8 & 96.4 & 81.2 & 96.4 \\
\hline$\Delta^{+}$ & 90.7 & 91.1 & 94.4 & 92.3 & 87.2 & 91.5 & 88.4 & 88.9 & 92.6 & 86.6 & 89.9 & 86.6 \\
\hline$s \Delta^{+}$ & 1542 & 547 & 567 & 738 & 1569 & 915 & 796 & 889 & 833 & 779 & 719 & 779 \\
\hline$\Lambda^{+}$ & 297 & 217 & 136 & 208 & 343 & 205 & 306 & 309 & 208 & 476 & 285 & 445 \\
\hline Eco-Ex & - & - & 7 & 31 & - & - & 33 & 427 & - & - & 15 & 307 \\
\hline \multirow[t]{2}{*}{ Sp Eco-Ex } & - & - & 159 & 348 & - & - & 166 & 215 & - & - & 11 & 201 \\
\hline & \multicolumn{4}{|l|}{ E7 } & \multicolumn{4}{|l|}{ E8 } & \multicolumn{4}{|l|}{ E9 } \\
\hline$S$ & 12 & 4 & 7 & 10 & 9 & 8 & 9 & 9 & 9 & 3 & 5 & 5 \\
\hline Shannon & 1.61 & 1.44 & 1.66 & 2.39 & 1.93 & 2.35 & 1.47 & 1.68 & 2.31 & 0.35 & 0.83 & 1.38 \\
\hline Margalef & 1.57 & 0.71 & 0.81 & 1.43 & 1.25 & 1.18 & 0.98 & 1.15 & 1.37 & 0.38 & 0.72 & 0.8 \\
\hline$\Delta$ & 42.6 & 51.6 & 56.2 & 69.7 & 47.7 & 72.6 & 40.9 & 47.6 & 62.2 & 10.1 & 24.6 & 42.7 \\
\hline$\Delta^{*}$ & 81.9 & 95.9 & 97.6 & 93.2 & 84.4 & 95.3 & 85.4 & 78.4 & 85.3 & 99.4 & 96.1 & 91.5 \\
\hline$\Delta^{+}$ & 93.6 & 94.4 & 92.9 & 90.7 & 90 & 94.1 & 94.6 & 94.1 & 89.8 & 83.3 & 95.0 & 91.7 \\
\hline$s \Delta^{+}$ & 1030 & 378 & 650 & 907 & 719 & 752 & 757 & 752 & 808 & 250 & 475 & 367 \\
\hline$\Lambda^{+}$ & 217 & 154 & 174 & 266 & 304 & 183 & 140 & 183 & 313 & 556 & 114 & 162 \\
\hline Eco-Ex & - & - & 311 & 85 & - & - & 72 & 7 & - & - & 3 & 2 \\
\hline \multirow[t]{2}{*}{ Sp Eco-Ex } & - & - & 119 & 83 & - & - & 180 & 70 & - & - & 146 & 2 \\
\hline & \multicolumn{4}{|l|}{ E10 } & \multicolumn{4}{|l|}{ E11 } & E12 & & & \\
\hline$S$ & 3 & 5 & 4 & 10 & 4 & 8 & 10 & 4 & 6 & 0 & 7 & 2 \\
\hline Shannon & 1.50 & 0.96 & 1.36 & 2.4 & 1.85 & 2.45 & 2.96 & 1.84 & 1.56 & - & 2.14 & 0.65 \\
\hline Margalef & 0.77 & 0.72 & 0.89 & 1,53 & 0.95 & 1.38 & 1.99 & 0.9 & 0.99 & - & 1.26 & 0.27 \\
\hline$\Delta$ & 63.1 & 25.3 & 47.7 & 44.5 & 59.7 & 69.6 & 74.2 & 67.7 & 39.5 & - & 69.0 & 28.5 \\
\hline$\Delta^{*}$ & 93.3 & 81.7 & 95.8 & 59.2 & 100 & 90.1 & 87.5 & 94.1 & 74.1 & - & 95.4 & 100 \\
\hline$\Delta^{+}$ & 88.9 & 86.7 & 83.3 & 85.2 & 100 & 90.5 & 86.3 & 97.2 & 76.7 & - & 84.4 & 100 \\
\hline$s \Delta^{+}$ & 267 & 433 & 333 & 852 & 300 & 724 & 863 & 389 & 460 & - & 507 & 200 \\
\hline$\Lambda^{+}$ & 247 & 267 & 278 & 410 & 0 & 247 & 374 & 39 & 289 & - & 425 & 0 \\
\hline Eco-Ex & - & - & 21 & 5 & - & - & 3416 & 2 & - & - & 60 & 3 \\
\hline Sp Eco-Ex & - & - & 123 & 51 & - & - & 230 & 221 & - & - & 59 & 322 \\
\hline & E1 & & & & & & E14 & & & & & \\
\hline & 90 & & 92 & 98 & & 00 & 90 & & 92 & 98 & & 00 \\
\hline$S$ & 1 & & 4 & 8 & & 3 & 5 & & 3 & 3 & & 7 \\
\hline Shannon & & 95 & 1.75 & & & 1.37 & 1.20 & & 0.55 & & & 2.04 \\
\hline Margalef & & 95 & 0.73 & & & 0.67 & 0.79 & & 0.36 & & & 1.23 \\
\hline$\Delta$ & & & 65.3 & 73 & & 58.9 & 35.4 & & 19.3 & 32 & & 57.1 \\
\hline$\Delta^{*}$ & & & 96.3 & 92 & & 100 & 88.8 & & 99.6 & 100 & & 86.2 \\
\hline$\Delta^{+}$ & & & 94.4 & 89 & & 100 & 90.0 & & 88.9 & 100 & & 89.7 \\
\hline$s \Delta^{+}$ & 97 & & 378 & 714 & & 300 & 450 & & 267 & 300 & & 628 \\
\hline$\Lambda^{+}$ & 30 & & 154 & 322 & & 0 & 233 & & 247 & 0 & & 224 \\
\hline Eco-Ex & - & & - & 6 & & 2 & - & & - & 4 & & 16 \\
\hline Sp Eco-Ex & - & & - & 202 & & 146 & - & & - & 222 & & 175 \\
\hline
\end{tabular}

$S$ : Species richness; $\Delta$ : Taxonomic diversity; $\Delta^{*}$ : Taxonomic Distinctness; $\Delta^{+}$: Average Taxonomic Distinctness (presence/absence of species); $s \Delta^{+}$: Total Taxonomic Distinctness; $\Lambda^{+}$: Variation in Taxonomic Distinctness. 
organic enriched areas, in the case of Mar Menor, and (c) between experimental and control plots, in the case of the Papoa beach field experiment.

\section{Results}

\subsection{Mondego estuary}

\subsubsection{Subtidal communities}

Values estimated for the different indices are summarised in Table 1. It becomes clear that most of the sampling stations do not show differences when we account for the Average Taxonomic Distinctness values (Fig. 2). In fact, even in the stations where just a few species were observed (e.g. E12 and E13 in 2000; E14 in 1998), the Average Taxonomic Distinctness measures present higher values, and suggesting therefore high path length between species through the tree. On the contrary, the Shannon-Wiener and Margalef indices, and Total Taxonomic Distinctness (TTD) showed low values in these faunal impoverished stations, and a high correlation $(r=0.99, p<0.005)$ was found between the Margalef index and TTD. The fact that those stations were far from the sea influence could lead us to think that salinity is a determining factor in the number of species. However, average salinity in those stations did not differ significantly from the rest $(p>0.05)$, and no significantly correlation was shown between salinity and specific enrichment either, as well as with the different indices applied (Table 1). In fact, other stations like E7 and E6 showed similar values of salinity or even lower (17 psu and 16 psu, respectively) than stations E12, E13 and E14, nonetheless, the number of species was greater than in the above mentioned stations (Table 1).

None of the indices showed significant differences $(p>0.05)$ among the various sampled years, although all of them indicate an improvement in the environmental quality status in 2000, namely in the south arm stations, which coincided with the implementation of impact mitigation practices from 1999. In spatial terms, the Margalef index and TTD were the only two indicators that clearly $(p<0.05)$ discriminated between the north and south arms sampling stations.

\subsubsection{Intertidal communities}

With regard to intertidal communities along the gradient of eutrophication symptoms in the south arm of the estuary, TTD was able to discriminate between the three sampling areas, showing higher values at the Zostera noltii beds and lower values at the most eutrophic area (Table 2). Also, the Margalef index and Eco-Exergy index varied as theoretically expected, exhibiting higher values at the Zostera sp. meadows and lower values at the inner areas of the south arm, although being unable to differentiate the intermediate eutrophic area from the most heavily eutrophic one. On the

Table 2

Groups obtained after the application of a Kruskal-Wallis analysis

\begin{tabular}{llll}
\hline & \multicolumn{2}{l}{ Average } & \\
\cline { 2 - 4 } & $s \Delta^{+}$ & Eco-Exergy & Margalef \\
\hline $\begin{array}{c}\text { Non-eutrophic area } \\
\quad \text { (Zostera } \text { meadows) }\end{array}$ & 2348 & 35048 & 2.3 \\
Intermediate eutrophic area & 1919 & 10143 & 2.1 \\
Eutrophic area & 1542 & 14893 & 1.6 \\
Groups & 1-NEA & 1-NEA & 1-NEA \\
& 2-IA & 2-IA,EA & 2-IA, EA \\
& 3-EA & &
\end{tabular}

(NEA: Non-eutrophic area; IA: Intermediate eutrophic area; EA: Eutrophic area). Total Taxonomic Distinctness $\left(s \Delta^{+}\right)$, Margalef and Eco-Exergy indices were the ones that significantly distinguished different areas in the intertidal area of Mondego estuary $(p \leqslant 0.05)$.

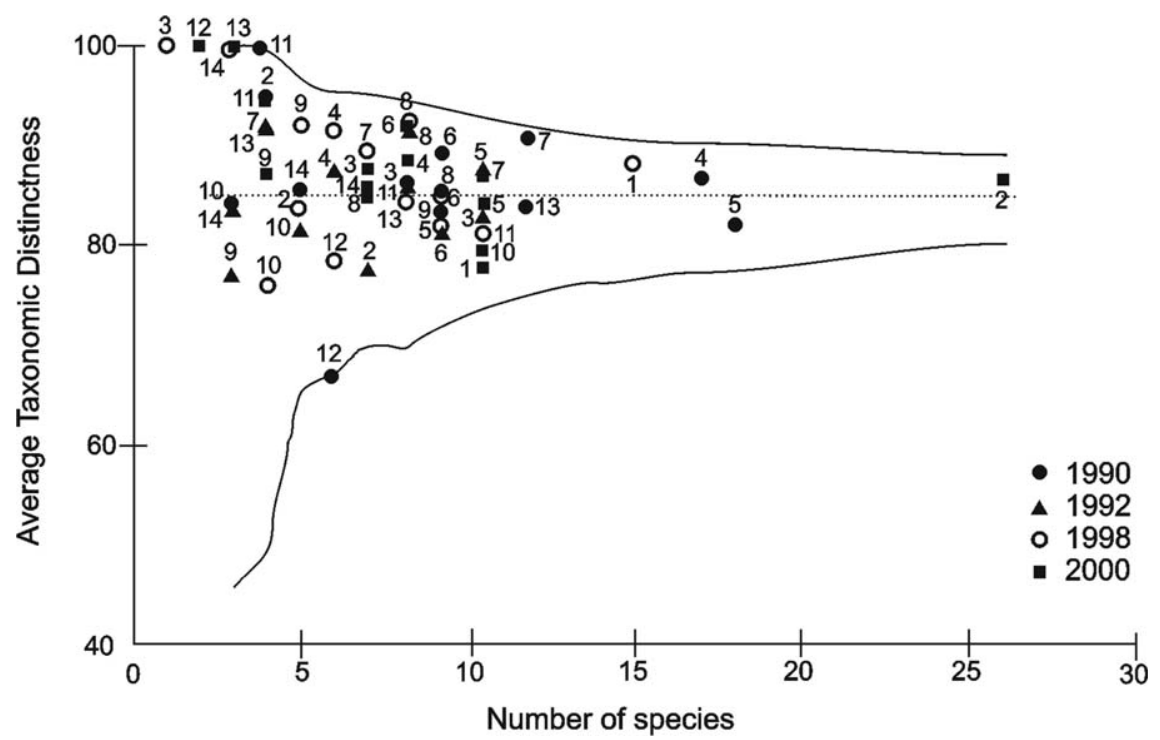

Fig. 2. Confidence funnel (mean and $95 \%$ confidence interval) of the Average Taxonomic Distinctness in the Mondego estuary subtidal stations (numbers above the symbols correspond to station number) in 1990, 1992, 1998 and 2000. 

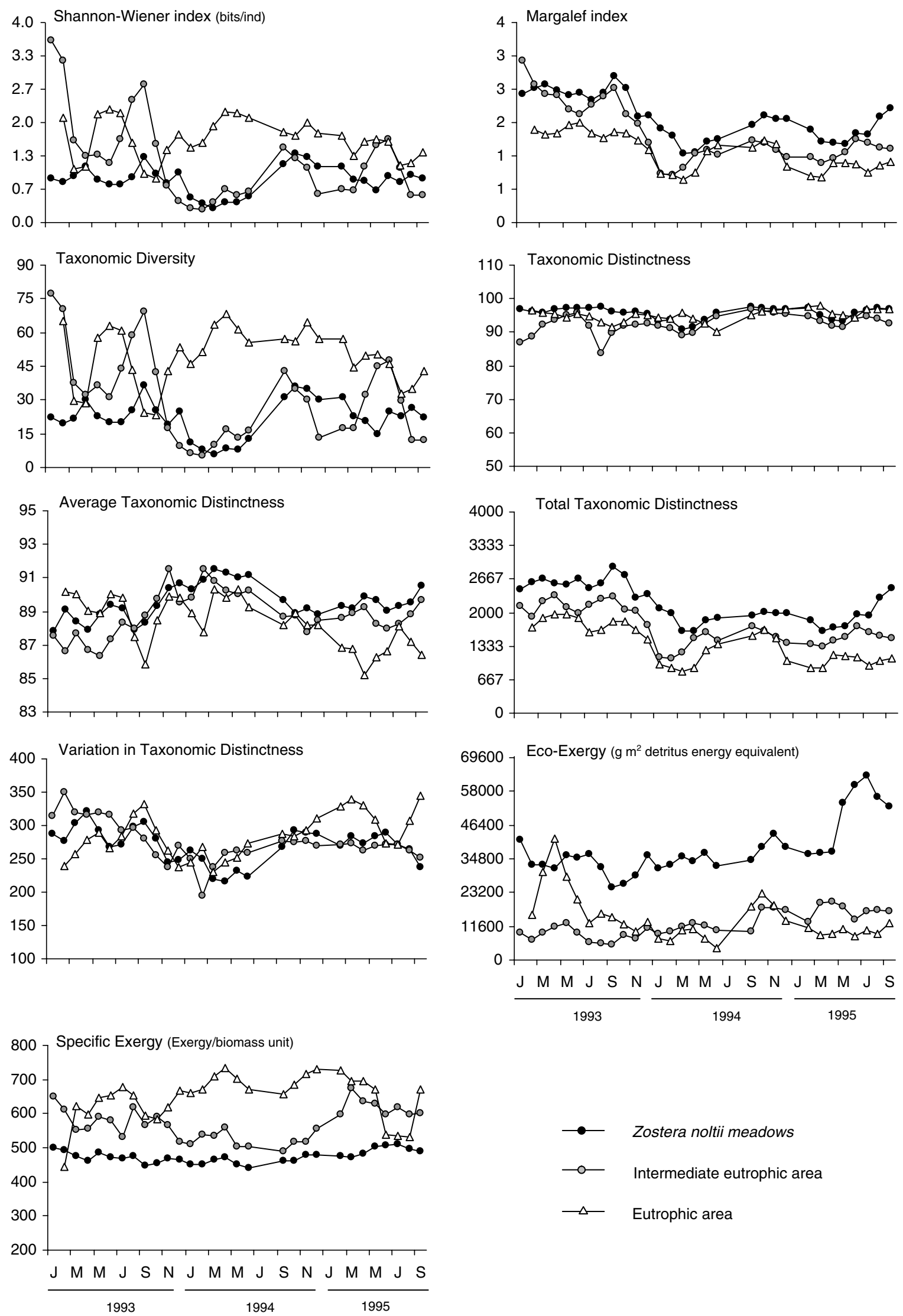

Fig. 3. Temporal and spatial variation of the applied indices in the south arm of the Mondego estuary. 
Table 3

Pearson's correlations between values of different indices in Mondego estuary (intertidal) and Mar Menor lagoon

\begin{tabular}{llll}
\hline & Organic matter & Salinity & Silt $(\%)$ \\
\hline Mondego estuary & & & \\
Eco-Exergy & $-0.62^{*}$ & - & - \\
Total Taxonomic Distinctness & $-0.76^{* *}$ & - & - \\
Margalef & $-0.64^{*}$ & - & - \\
Mar Menor lagoon & & & \\
Eco-Exergy & $-0.49^{*}$ & $-0.60^{*}$ & -0.39 \\
Total Taxonomic Distinctness & $-0.69^{*}$ & +0.27 & $-0.69^{*}$ \\
Margalef & $-0.68^{*}$ & $-0.60^{*}$ & $-0.77^{*}$ \\
Shannon-Wiener & $-0.67^{*}$ & $-0.61^{*}$ & $-0.70^{*}$ \\
\hline${ }^{*} p<0.05$. & & & \\
${ }^{* *} \quad$ & & &
\end{tabular}

contrary, the Shannon-Wiener index, the Taxonomic Diversity, the Taxonomic Distinctness and Specific Exergy indicated that environmental quality status was better at the most eutrophic area, which obviously is not in agreement with our knowledge of the system (Fig. 3).

The TTD, the Margalef index, and the Eco-Exergy index, all capable of discriminating the Zostera noltii meadows from the rest of the system, are positively and significantly correlated with the organic matter in the sediment (Table 3). Moreover, the Margalef index and Eco-Exergy are negatively correlated with the ammonium and nitrite concentration in the water column (Margalef index vs Nitrite concentration: $r=-0.25, p<0.05$; Eco-Exergy vs ammonium concentration: $r=-0.30, p<0.05)$. This indicates some response to the fact that, although indirectly, in the Mondego estuary, the benthic communities structure is negatively influenced by the concentration of nutrients in the water column, which is related with the overall eutrophication of the system, expressed by the occurrence of green macroalgal blooms (Marques et al., 2003).

\subsection{Mar Menor}

According to the hypothesis tested by Warwick and Clarke (1995) it would be expected that Taxonomic Distinctness measures should be able of elucidating pollution effects. However, only TTD, in parallel with the Margalef index, were both able to detect significant differences between organically enriched and non-organically enriched areas $(p<0.05)$ in soft bottom zones and in rocky ones.

In the majority of the stations, both Average Taxonomic Distinctness $\left(\Delta^{+}\right)$and Variation in Taxonomic Distinctness $\left(\Lambda^{+}\right)$were within the $95 \%$ confidence funnel $(p \geqslant 0.05)$ (Fig. 4), implying a good degree of taxonomic stability. Only station M8, characterised by the presence of nitrophyle communities, appeared out of the confidence funnel, as the few species found (Eq. (7)) belong only to two orders (Tanaidacea and Amphipoda), grouped in four families, indicating a low structural complexity in the community.

The Shannon-Wiener and Margalef indices, Eco-Exergy and TTD appeared all negatively and significantly corre- lated $(p \leqslant 0.05)$ with the organic matter content in sediments and salinity. The Margalef and Shannon-Wiener indices and TTD were also negatively correlated with sediments particle size (Table 3).

Moreover, Specific Exergy showed a clear positive correlation with the presence of certain heavy metals such as $\mathrm{Pb}$ $(r=0.89, p \leqslant 0.05)$ and $\mathrm{Zn}(r=0.71, p \leqslant 0.05)$, which does not correspond to what theoretically should be expected. Station M2D, for instance, which presented the highest concentration of these two heavy metals ( $\mathrm{Pb}$ : $3300 \mathrm{ppm}$; Zn: 3400 ppm), also exhibited the highest values of Specific Exergy (Table 4). Nevertheless, this can be explained if we account for the fact that, in the case of Specific Exergy, biomass fluctuations have much less influence in the values estimated than changes in the quality of the biomass, which are reflected in the $\beta$-values. Molluscs, namely bivalves, are more tolerant to heavy metals contamination, due to their ability to bio-accumulate them, and have higher $\beta$-factors than less tolerant groups like polychaetes, crustaceans and echinoderms. Therefore, despite the general macrofaunal impoverishment in areas contaminated by heavy metals, molluscs are comparatively better represented (e.g. Venerupsis aurea in station M2) than other groups, and it becomes immediately easy to understand why values of Specific Exergy are higher.

\subsection{Papoa}

In general, indicators based on species richness (Margalef and Shannon-Wiener indices) and TTD showed higher values in the control plots until September 1999 (seven months after the physical disturbance), but a shift is then recognisable. In fact, from September 1999 up to the end of the study period, the experimental plots representing the recovering community presented higher values than the control plots. Furthermore, the values of Margalef index (Fig. 5) were always higher at the recovery community, except in the very beginning of the experiment, when the control assemblage, understandably exhibited higher values. Accordingly, the Shannon-Wiener index (Fig. 5) was higher at the recovering plots from September 1999 until the end of the study period.

Taxonomic Diversity, Taxonomic Distinctness, Average Taxonomic Distinctness and Variation in Taxonomic Distinctness showed similar values in control and experimental plots (Fig. 5), suggesting the same degree of complexity in both cases.

With regard to Eco-Exergy (Fig. 5), values estimated for the experimental plots increased gradually throughout the field experiment, converging towards those observed in the control plots by the end of the study period. Finally, Specific Exergy (Fig. 5) showed nearly comparable values in the experimental and control plots after only one month of recovery, expressing therefore a more or less identical structural complexity in both cases. Nevertheless, this index showed always slightly lower values in the community under recovery. 

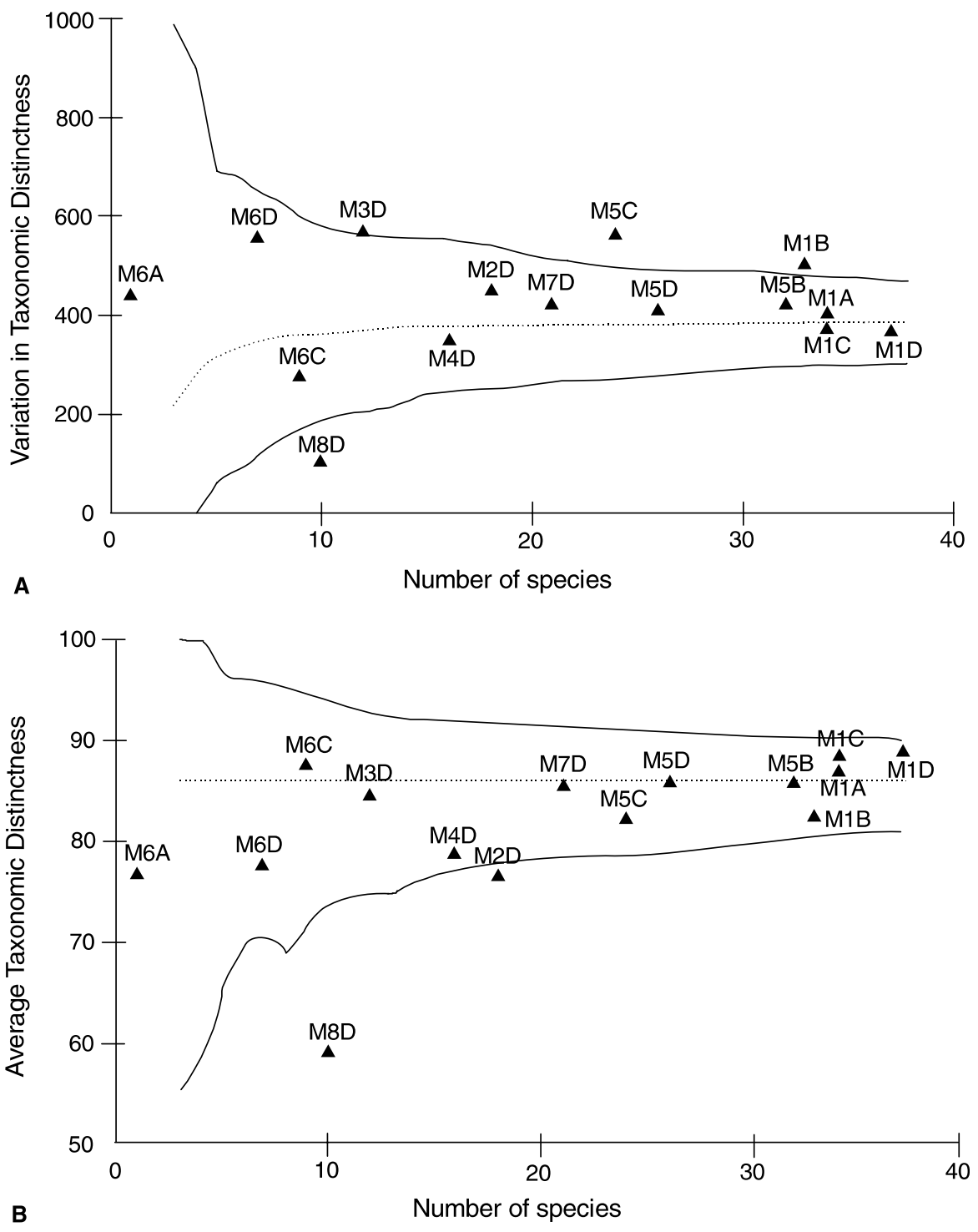

Fig. 4. Confidence funnel (mean and $95 \%$ confidence interval) of the Variation in Taxonomic Distinctness (A) and Average Taxonomic Distinctness (B) in the Mar Menor lagoon.

Table 4

Indices values measured at different sampling stations in the Mar Menor lagoon

\begin{tabular}{|c|c|c|c|c|c|c|c|c|c|}
\hline & Shannon & Margalef & $\Delta$ & $\Delta^{*}$ & $\Delta^{+}$ & $s \Delta^{+}$ & $\Lambda^{+}$ & Eco-Exergy & Sp Ex \\
\hline M1A & 2.24 & 3.72 & 45.0 & 72.42 & 87.25 & 2966.67 & 403.52 & 2885503836 & 149346 \\
\hline M1B & 3.63 & 4.91 & 77.2 & 89.12 & 82.51 & 2722.92 & 532.79 & 183671203 & 155184 \\
\hline M1C & 2.19 & 3.87 & 43.71 & 72.74 & 88.15 & 2996.97 & 386.82 & 546460384 & 76725 \\
\hline M1D & 2.43 & 4.32 & 49.77 & 77.22 & 88.46 & 3273.15 & 370.33 & 192624681 & 70963 \\
\hline M2D & 2.75 & 2.13 & 56.45 & 68.89 & 85.10 & 1021.21 & 514.55 & 15762446 & 603402 \\
\hline M3D & 2.06 & 3.20 & 42.48 & 79.71 & 77.67 & 1398.04 & 418.17 & 211020 & 1592 \\
\hline M4D & 2.71 & 3.20 & 51.78 & 69.85 & 79.03 & 1264.44 & 340.26 & 2523455 & 14250 \\
\hline M6A & - & 0.00 & 0.00 & 0.00 & 0.00 & 0.00 & 0.00 & 285182 & 14990 \\
\hline M5B & 2.46 & 3.87 & 46.34 & 63.63 & 85.25 & 2727.96 & 430.36 & 899957796 & 109861 \\
\hline M5C & 2.55 & 3.26 & 46.10 & 61.49 & 82.19 & 1972.46 & 575.37 & 76867912 & 102457 \\
\hline M6C & 1.44 & 1.78 & 38.33 & 87.56 & 87.96 & 791.67 & 287.21 & 94659 & 92702 \\
\hline M5D & 1.90 & 3.41 & 49.01 & 95.41 & 86.41 & 2246.67 & 407.63 & 145227127 & 94642 \\
\hline M6D & 1.18 & 1.24 & 25.20 & 70.92 & 76.98 & 538.89 & 621.06 & 1555244 & 109065 \\
\hline M7C & 2.00 & 2.50 & 41.98 & 72.67 & 85.79 & 1801.67 & 421.20 & 3249672701 & 94686 \\
\hline M8C & 2.75 & 1.76 & 47.24 & 58.27 & 59.26 & 592.59 & 105.62 & 301455400 & 70064 \\
\hline
\end{tabular}

$\Delta$ : Taxonomic diversity; $\Delta^{*}$ : Taxonomic Distinctness; $\Delta^{+}$: Average Taxonomic Distinctness (presence/absence of species); $s \Delta^{+}:$Total Taxonomic Distinctness; $\Lambda^{+}$: Variation in Taxonomic Distinctness; Sp Ex: Specific Exergy. 

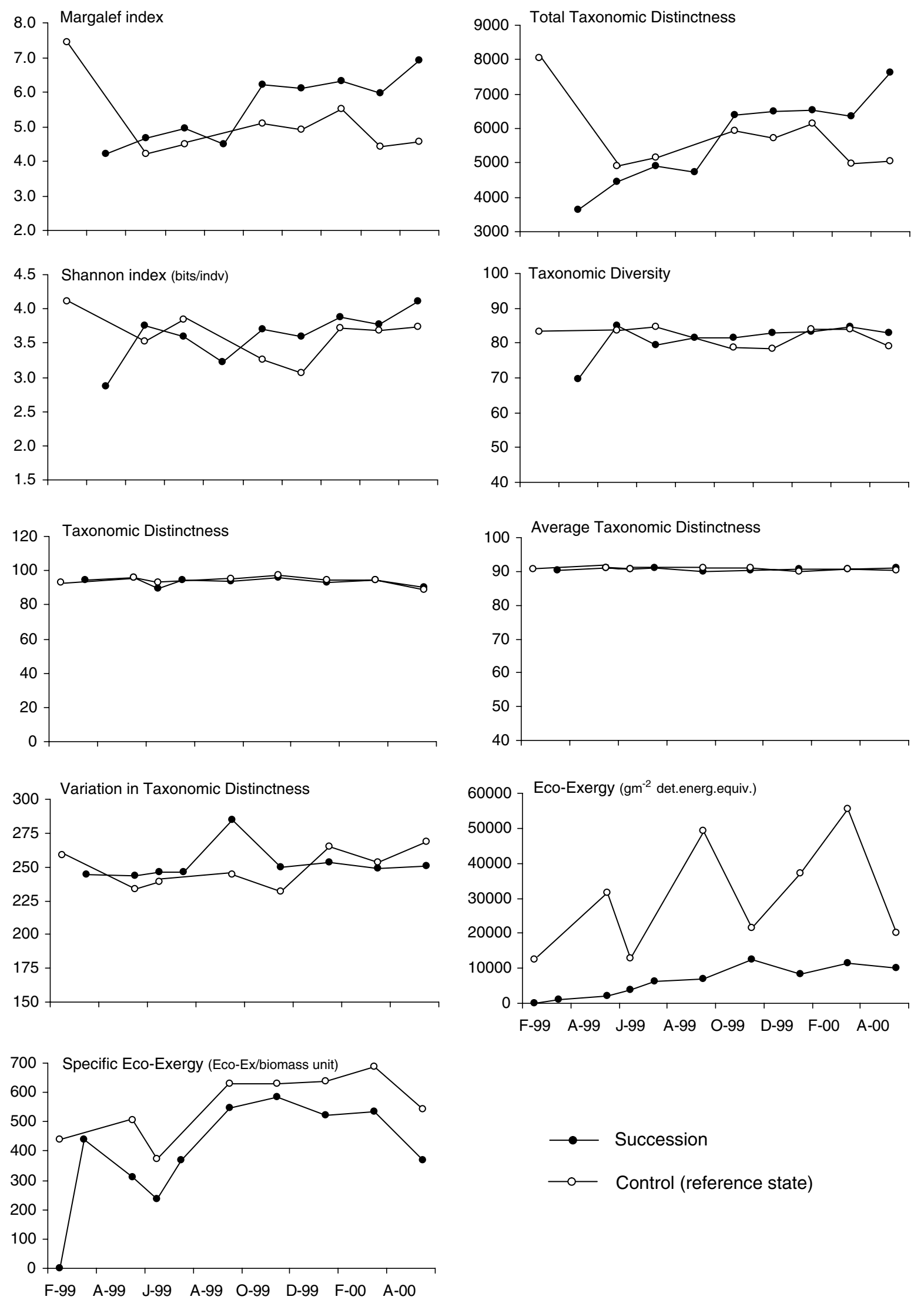

Fig. 5. Variation of the applied indices in the control and succession plots in Papoa. 


\section{Discussion}

Among the biological quality elements for the definition of ecological status in WFD are the composition and abundance of benthic invertebrate fauna. At least in theory, all ecological indicators accounting for those parameters might be useful in detecting the environmental quality status of an ecosystem. However, due to the fact that in practice most of them were developed to approach the characteristics of a specific ecosystem, they often lack generality. Others have been criticised or rejected due to their dependence of specific environmental parameters, or due to their unpredictable behaviour depending on the type of environmental stress. The choice of the ecological indicators set to use in a particular case is, therefore, a subtle process.

Prior et al. (2004), on the basis of the work developed by Somerfield et al. (2003) at Plymouth Marine Laboratory, proposed and tested the Average Taxonomic Distinctness to be used as a useful tool in the classification ecological status following the European Water Framework Directive. This is due to an advantage of this index proceeding from the fact that it incorporates a master list of taxa, which reflects what could be considered to represent reference conditions. Moreover, this index incorporates a statistical framework from which to measure the distance in relation to those reference conditions.

However, in view of these results, the Taxonomic Distinctness measures have been less sensitive than other diversity measures, despite having many of the features (e.g. independency on sample size/effort or monotonic response to environmental degradation) required in order to be a good biodiversity indicator. Therefore, these measures do not appear to be very useful in establishing the ecological status proposed by the WFD. Even more, along a clear gradient of eutrophication symptoms as at present in the south arm of the Mondego estuary, the Taxonomic Distinctness measures showed higher values in the most eutrophic area. Apparently, our observations do not support Warwick and Clarke (1995) statements regarding the monotonic behaviour shown by these indices along a gradient of increasing environmental degradation around an oilfield in the North Sea, and their capacity of being more sensitive indices of community perturbation than species diversity. Similarly, Somerfield et al. (1997) found no consistent pattern between decreasing Taxonomic Diversity of marine macrofaunal assemblages and increasing environmental impact in other oilfields in the North Sea. Hall and Greenstreet (1998), studying fish communities, found that Taxonomic Distinctness measures showed identical trends to conventional diversity indices.

Out of all taxonomic distinctness measures, only the TTD was able to correctly differentiate the eutrophication gradient present in the intertidal area of Mondego, apart from differentiating, more organically enriched areas in the Mar Menor. Nonetheless, Warwick and Clarke (1998) consider not recommendable the use of that measure due to, in general, TTD tends to track species richness rather closely, and it is only useful for tightly controlled designs in which effort is identical for the samples being compared, or sampling is sufficiently exhaustive for the asymptote of the species-area curve to have been reached.

In the same way, Margalef index performed better, despite its simplicity, compared to other indices based on the abundance of individuals, distinguishing between different eutrophication levels, (e.g. Mondego estuary intertidal area) and detecting organic enrichment situations as in the case of the Mar Menor lagoon. On the contrary, Shannon-Wiener index appears excessively influenced by the dominance of certain species (e.g. Hydrobia ulvae and Cerastoderma edule in the Mondego estuary or Bittium sp. in the Mar Menor) whose presence has no relation with any type of disturbance, being favoured by abundant food resources.

It is interesting to observe how the two tested indices based on specific richness (Margalef index and Total Taxonomic Distinctness) were the most successful measures in differentiating the diverse grades of pollution, leading us to think that the increment or decrement in the number of species is one of the best disturbance indicators, and therefore, essential when it comes to differentiating ecological status. The Northeast Atlantic Geographical Intercalibration Group Benthic Expert (NEAGIG, 2004) considered that the selected metrics to be used in the WFD context need to distinguish clearly across the good/moderate boundary. Obviously, those two measurements are not able themselves alone to work out such distinction, as they will always need a previous knowledge on the number of species (reference situation) of the studied site. In that sense, few are the indices capable of establishing the different ecological status (high, good, moderate, poor and bad). That is for instance the case of AMBI (Borja et al., 2000, 2003; Salas et al., 2004) or the BENTIX (Simboura and Zenetos, 2002), which were not tested in this particular work.

The other inconvenience of species richness is that, contrarily to Taxonomic Distinctness, it may be more sensitive to underlying variation in natural environmental factors, thus generating confounding effects if one is interested in the influence of anthropogenic perturbations (Warwick and Clarke, 1998; Leonard et al., in press). Indeed, the fact that AVTD sustained high values in Mondego stations with few species but low levels of organic matter and therefore not organically polluted, showed the ability of this index to detect impacts despite possible natural environmental disturbances, as for example salinity fluctuations, in an estuary or coastal lagoon. Those salinity fluctuations in the Mondego estuary do not seem to be the determining factor that influenced the richness of species. The previous mentioned measure can be affected by a number of factors, as for example the marine water and freshwater inputs, that 
make difficult the colonisation and settlement possibilities of certain species. Nevertheless, in the Mar Menor the salinity was a very influential parameter because it is correlated with the confinement or isolation degree in the lagoon (Gamito et al., 2005; Pérez-Ruzafa and Marcos, 1992; Pérez-Ruzafa et al., 2005).

Studies like Heino et al. (2005) showed that Taxonomic Distinctness also varies along natural gradients and it is unlikely that a site can be determined to be degraded or not degraded based only on the measure of Taxonomic Distinctness. On the other hand, although Average Taxonomic Distinctness has the ability to discriminate properly between polluted and non-polluted areas in those of low number of species (as it is the case of the subtidal communities in Mondego), the results of this study demonstrated that its power of discrimination decreases when the number or species increases (see confidence limits in the funnel graphic representation, Fig. 2), which leads us to think that the index is not able to show correlations with pollution in areas where richness depends on other factors.

Regarding the Eco-Exergy based indices, the results of the present study suggest that the Eco-Exergy index, as ecological indicator, captured, in fact, useful information about the state of the community. In the Mar Menor lagoon this index was able to respond to structural environmental variables such as organic matter, and salinity interval and Specific Exergy was sensitive to granulometry. However, the Eco-Exergy index did not provide, explicit information about disturbed (e.g. polluted) scenarios. On the other hand, in the Mondego estuary, both Exergy based indicators distinguished between areas with different eutrophication symptoms. Efficiency differences, in both case studies, might have been due to the fact that in the Mar Menor lagoon the effects of organic pollution are, in a certain extent, diluted among other system-structuring factors, while in the south arm of the Mondego estuary eutrophication is the major driving force behind the ongoing changes. However, in the Mondego estuary, only the Eco-Exergy index differentiated correctly the non-eutrophic zone from the rest. Specific Exergy showed the highest values in the eutrophic area due to the dominance of the bivalve molluscs which $\beta$-values are higher than in other groups, as it occurred in some of the stations in the Mar Menor.

In the Papoa case, through re-colonisation, Eco-Exergy values in experimental plots converged towards those observed in the control community. However, this trend appeared to reflect, essentially, changes in biomass, not in information (Patrício et al., in press). On the other hand, taking into account Specific Exergy, or average organism complexity (an average $\beta$-value), the community at the experimental plots rapidly recovered in terms of information. In fact, Specific Exergy, after only one month of experiment, showed already resembling values in the experimental and control plots and a parallel behaviour suggesting therefore an analogous structural complexity in both assemblages. Yet, this index showed always inferior values in the community under recovery. A problem with EcoExergy based indices is the obvious lack of discriminating power of the weighting factors used to estimate these indices once organisms are considered at very high taxonomic levels. Although, the assessment of $\beta$-values still constitutes a weak point, Jørgensen et al. (2005) present an expanded list that contains $45 \beta$-values, which hopefully will improve the use of these values to calculate the Eco-Exergy for assessment of ecosystem condition. The authors state that the previous found $\beta$-values (the ones available by the time this study was carried out) are most probably too small as they only account for the non-nonsense genes in estimating the $\beta$-values. On the other hand, it is stated that the application of the previous values for the assessment of ecosystem health and in the development of structurally dynamic models have been satisfactorily robust, so Jørgensen et al. (2005) conclude that the previously obtained results are valid. Despite this difficulty, both the thermodynamic oriented indices have provided useful information about the structural development of the community, although at the present stage, the Eco-Exergy index it is still not tested in an ample number of situations to be used as a tool for WFD application.

In conclusion, although some of the measures taken into consideration in this work have been effective in differentiating the various disturbance statuses, none of them (and specially the Taxonomic Distinctness measures) seems to be particularly helpful alone in assessing the five systems' ecological status with regard to the WFD implementation.

\section{Acknowledgements}

The present work was carried out in the scope of the research Project DYNAMOD (POCTI/M6S137431/2001) and supported by FCT (Portuguese National Board of Scientific Research) through a Grant SFRH/BD/820/2000.

\section{References}

Barcala, E., 1999. Estudio ecológico de la ictiofauna bentónica del Mar Menor. PhD. Thesis, University of Murcia, Spain.

Borja, A., Franco, J., Pérez, V.A., 2000. Marine Biotic Index to establish the ecological quality of soft-bottom benthos within European estuarine and coastal environments. Marine Pollution Bulletin 40 (12), 1100-1114.

Borja, A., Muxika, I., Franco, J., 2003. The application of a Marine Biotic Index to different impact sources affecting soft-bottom benthic communities along European coasts. Marine Pollution Bulletin 46 (7), 835-845.

Cardoso, P.G., Pardal, M.A., Lillebø, A.I., Ferreira, S.M., Raffaelli, D. Marques, J.C., 2004. Dynamic changes in seagrass assemblages under eutrophication and implications for recovery. Journal of Experimental Marine Biology and Ecology 302, 233-248.

Clarke, K.R., Warwick, R.M., 1998. A taxonomic distinctness index and its statistical properties. Journal of Applied Ecology 35, 523-531.

Clarke, K.R., Warwick, R.M., 2001. A further biodiversity index applicable to species lists: variation in taxonomic distinctness. Marine Ecology Progress Series 216, 265-278.

Costello, M.J., Pohle, G., Martin, A., 2004. Evaluating biodiversity in marine environmental assessments. Research and Development Mono- 
graph Series 2001, Canadian Environmental Assessment Agency, Ottawa.

EC, 2000. Directive of the European Parliament and of the Council 2000/ 60/EC establishing a framework for community action in the field of water policy PE-CONS 3639/1/00, p. 72.

Gamito, S., Gilabert, J., Marcos Diego, C., Pérez-Ruzafa, A., 2005. Effects of changing environmental conditions on lagoon ecology. In: Gönenc, J.E., Wolflin, J. (Eds.), Coastal Lagoons: Ecosystem Processes and Modelling for Sustainable Use and Development. CRC Press, Boca Raton, pp. 193-229.

Gray, J.S., 2000. The measurement of marine species diversity, with an application to the benthic fauna of the Norwegian continental shelf. Journal of Experimental Marine Biology and Ecology 250, 23-49.

Hall, S.J., Greenstreet, S.P., 1998. Taxonomic distinctness and diversity measures: responses in marine fish communities. Marine Ecology Progress Series 166, 227-229.

Heino, J., Soininen, J., Lappalainen, J., Virtanen, R., 2005. The relationship between species richness and taxonomic distinctness in freshwater organisms. Limnology and Oceanography 50 (3), 978-986.

Jørgensen, S.E., Mejer, H., 1979. A holistic approach to ecological modelling. Ecological Modelling 7, 169-189.

Jørgensen, S.E., 2002. Integration of Ecosystem Theories: A Pattern, third ed. Kluwer Academic Publ. Comp., Dordrecht, The Netherlands, p. 432.

Jørgensen, S.E, Ladegaard, N., Debeljak, M., Marques, J.C. Calculations of exergy for organisms. Ecological Modelling, in press.

Leonard, D.R.P., Clarke, K.R., Somerfield, P., Warwick, R.M. The application of an indicator based on taxonomic distinctness for UK marine biodiversity assessments. Journal of Environmental Management, in press.

Marques, J.C., Pardal, M.A., Nielsen, S.N., Jørgensen, S.E., 1997. Analysis of the properties of exergy and biodiversity along an estuarine gradient of eutrophication. Ecological Modelling 102, 155-167.

Marques, J.C., Nielsen, S.N., Pardal, M.A., Jørgensen, S.E., 2003. Impact of eutrophication and river management within a framework of ecosystem theories. Ecological Modelling 166, 147-168.

Martins, I., Pardal, M.A., Lillebø, A.I., Flindt, A.R., Marques, J.C., 2001. Hydrodynamics as a major factor controlling the occurrence of green macroalgal blooms in a eutrophic estuary: a case study on the influence of precipitation and river management. Estuarine Coastal and Shelf Science 52, 165-177.

NEAGIG, 2004. Minutes of Northeast Atlantic Geographical Intercalibration Group Benthic Expert Meeting. Kristineberg Marine Station, Sweden, 22-24 September 2004.

Pardal, M.A., Marques, J.C., Metelo, I., Lillebø, A.I., Flindt, M.R., 2000. Impact of eutrophication on the life cycle population dynamics and production of Ampithoe valida (Amphipoda) along an estuarine spatial gradient (Mondego estuary, Portugal). Marine Ecology Progress Series 196, 207-219.

Pardal, M.A., Cardoso, P.G., Sousa, J.P., Marques, J.C., Raffaelli, D., 2004. Assessing environmental quality: a novel approach. Marine Ecology Progress Series 267, 1-8.

Patrício, J., Salas, F., Pardal, M.A., Marques, J.C., Jørgensen, S.E. Ecological indicators performance during a re-colonisation field experiment and its compliance with ecosystem theories. Ecological Indicators, in press.

Pérez-Ruzafa, A., Marcos, C., Pérez-Ruzafa, I.M., Ros, J.D., 1987. Evolución de las características ambientales y de los poblamientos del Mar Menor (Murcia, SE de España). Anales de Biología 12(Biología ambiental 3), 53-65.

Pérez-Ruzafa, A., Ros, J.D., Marcos, C., Ballester, R., Pérez-Ruzafa, I.M., 1989. Distribution and biomass of the macrophyte beds in a hypersaline coastal lagoon (the Mar Menor, SE Spain), and its recent evolution following major environmental changes. In: Boudoresque, C.F., Meinenesz, A., Fresi, E., Gravez, V. (Eds.), International Workshops on Posidonia Beds. GIS Posidonie Publications, Fr. 2, pp. 49-62.

Pérez-Ruzafa, A., Marcos, C., Ros, J.D., 1991. Environmental and biological changes selected to recent human activities in the Mar Menor (S.E. Spain). Marine Pollution Bulletin 23, 747-751.

Pérez-Ruzafa, A., Marcos, C., 1992. Colonization rates and dispersal as essential parameters in the confinement theory to explain the structure and horizontal zonation of lagoon benthic assemblages. Rapp. Comm. int. Mer Medit. 33, 100.

Pérez-Ruzafa, A., Navarro, S., Barba, A., Marcos, C., Camara, M.A., Salas, F., Gutierrez, J.M., 2000. Presence of pesticides throughout trophic compartments of the food web in the Mar Menor Lagoon (S.E. Spain). Marine Pollution Bulletin 40 (2), 140-151.

Pérez-Ruzafa, A., Marcos, C., Gilbert, J., 2005. The ecology of the Mar Menor coastal lagoon: a fast changing ecosystem under human pressure. In: Gönenc, J.E., Wolflin, J. (Eds.), Coastal Lagoons: Ecosystem Processes and Modelling for Sustainable Use and Development. CRC Press, Boca Raton, pp. 392-422.

Prior, A., Miles, A.C., Sparrow, A.J., Price, N., 2004. Development of a classification scheme for the marine benthic invertebrate component, Water Framework Directive. Phase I \& II - Transitional and coastal waters. R\&D Interim Technical Report E1-116/E1-132, p. 103.

Rogers, S.I., Clarke, K.R., Reynolds, J.D., 1999. The taxonomic distinctness of coastal bottom-dwelling fish communities of the North-east Atlantic. Journal of Animal Ecology 68, 769-782.

Salas, F., Neto, J.M., Borja, A., Marques, J.C., 2004. Evaluation of the applicability of a marine biotic index to characterise the status of estuarine ecosystems: the case of Mondego estuary (Portugal). Ecological Indicators 4, 215-225.

Simboura, N., Zenetos, A., 2002. Benthic indicators to use ecological quality classification of Mediterranean soft bottom marine ecosystems, including a new biotic index. Mediterranean Marine Science 3/2, 77 111.

Somerfield, P.J., Olsgard, F., Carr, M.R., 1997. A further examination of two new taxonomic distinctness measures. Marine Ecology Progress Series 154, 303-306.

Somerfield, P.J., Clarke, K.R., Warwick, R.M., 2003. Taxonomic distinctness as an indicator of biodiversity and environmental health: analysis of data and draft recommendations. Plymouth Marine Laboratory, Plymouth.

UNEP (United Nations Environmental Programme), 1992. Convention on biological diversity-text and annexes. Chatelaine, Switzerland: Secretariat for the Convention on Biological Diversity, p. 34.

Van der Spoel, S., 1994. A biosystematic basis for pelagic biodiversity. Bijdragen tot de Diekunde 64, 3-31.

Warwick, R.M., Clarke, K.R., 1995. New biodiversity measures reveal a decrease in taxonomic distinctness with increasing stress. Marine Ecology Progress Series 129, 301-305.

Warwick, R.M., Clarke, K.R., 1998. Taxonomic distinctness and environmental assessment. Journal of Applied Ecology 35, 532-543.

Warwick, R.M., Light, J., 2002. Death assemblages of molluscs on St Martin's Flats, Isles of Scilly: a surrogate for regional biodiversity. Biodiversity and Conservation 11, 99-112.

Warwick, R.M., Ashman, C.M., Brown, A.R., Clarke, K.R., Dowell, B., Hart, B., Lewis, R.E., Shillabeer, N., Somerfield, P.J., Tapp, J.F., 2002. Inter-annual changes in the biodiversity and community structure of the macrobenthos in Tees Bay and the Tees estuary, UK, associated with local and regional environmental events. Marine Ecology Progress Series 234, 1-13.

Wilkinson, D.M., 1999. The disturbing history of intermediate disturbance. Oikos 84, 145-147. 